\title{
Detection of empty grate regions in firing processes using infrared cameras
}

\author{
by J. Matthes*, P. Waibel* and H.B. Keller*
}

*Institute for Applied Computer Science, Karlsruhe Institute of Technology, Hermann-von-Helmholtz-Platz 1, 76344 Eggenstein-Leopoldshafen, Germany, joerg.matthes|patrick.waibel|hubert.keller@kit.edu

\begin{abstract}
Recently, infrared cameras are used in grate firing processes for waste and biomass incineration in order to optimize the process control. These infrared (IR) cameras with a bandpass filter at 3.8 to $4.0 \mu \mathrm{m}$ allow for a detailed measurement of the solid bed's temperature distribution. Additionally, the current load condition of the grate is of interest for the process control, which cannot be measured so far. In this paper a new image processing algorithm is presented, which extracts detailed information about the load condition for each grate zone from the IR-images. The new algorithm is based on a correlation method using prior domain knowledge (template) in order to increase the reliability of the calculated parameters.
\end{abstract}

\section{Introduction}

\subsection{Principle of camera aided control of grate firing processes}

Figure 1 depicts the considered type of a grate firing combustion plant which runs typically with changing fuels like biomass or waste.

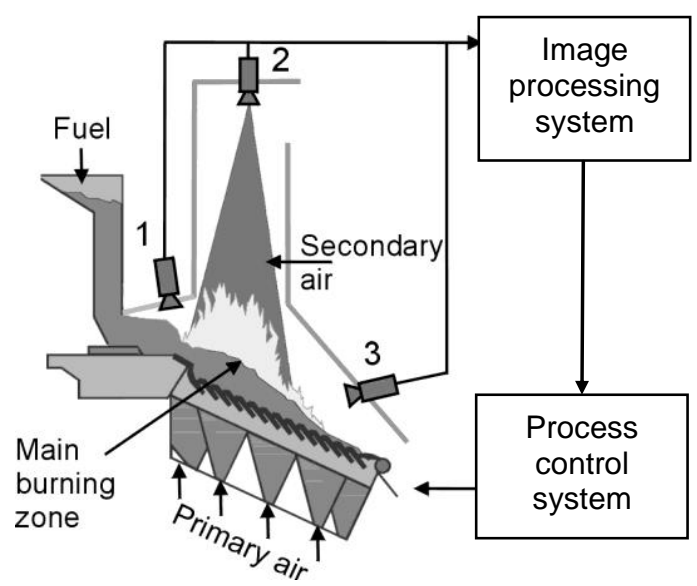

Fig. 1. Grate firing plant with camera aided combustion control scheme

The fuel enters the grate and passes a drying, pyrolysis, and ignition phase before the burning down begins from the fuel bed surface. The grate is subdivided into controllable zones and lanes. The primary air flows through the grate from below. Since the primary air does not ensure complete gas burning out, secondary air is injected above the fuel bed. The hot flue gas then passes a boiler to produce steam. One of the main control objectives is a constant steam production, but changing and heterogeneous fuel properties lead to a local different and non-stationary combustion. Using additional process information from special infrared cameras with a bandpass filter installed at positions 2 or 3 (Fig. 1) combined with an image processing system like "INSPECT pro control", the combustion control can be improved significantly $[1,2]$.

\subsection{Camera technologies for monitoring firing processes}

Absolute temperatures of the combustion process on the grate (primary process of thermal waste treatment) can only be measured by IR cameras using a bandpass filter in the range of 3.8 to $4.0 \mu \mathrm{m}$. Video cameras are subject to major restrictions, as they cannot see through flames.

Both soot radiation and emissions of gas components are nearly negligible in the range of $3.9 \mu \mathrm{m}$. Figure 2 exposes the emissivities of the relevant gas components in a typical burning chamber atmosphere. Furthermore the influence of soot in the gas phase is depicted. Due to the decreasing influence of the soot in the flame, in the IR-range the flames are almost transparent (see Figure 2 right). 

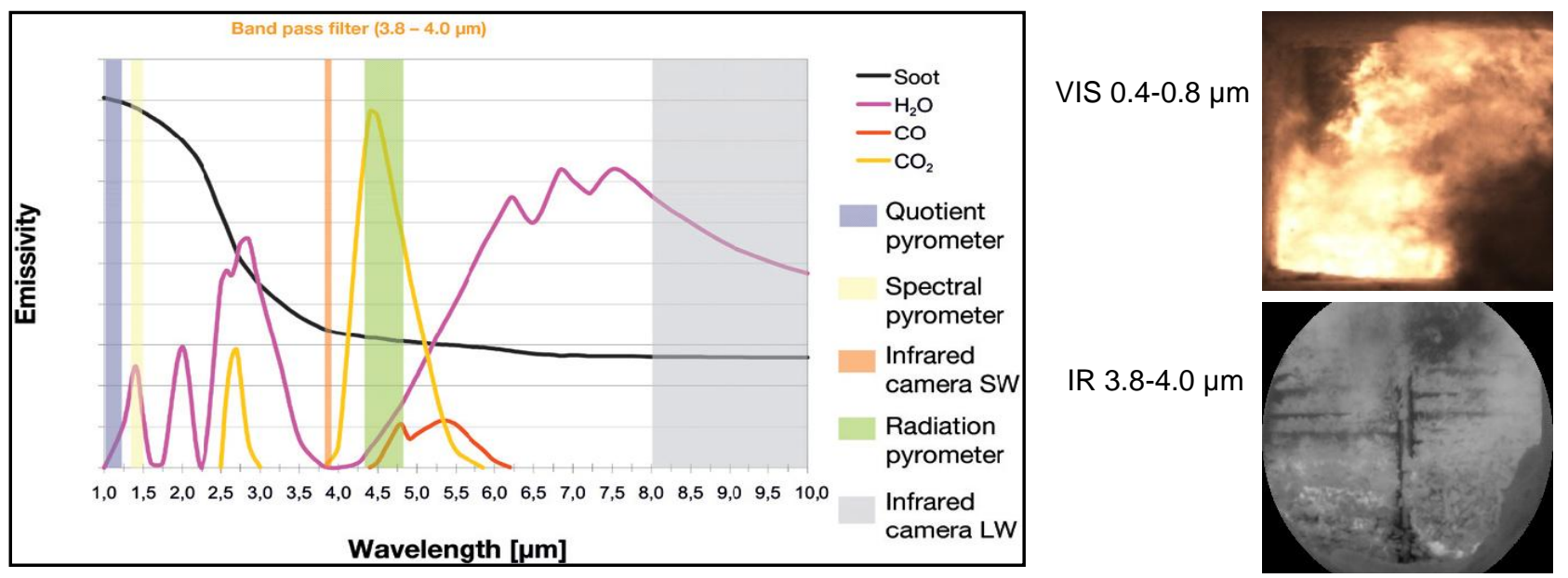

Fig. 2. Emissivity of gas components, soot with transparency window (left), VIS and IR image from position 2 (right) [2].

IR cameras with bandpass filter at $3.9 \mu \mathrm{m}$ are available with micro-bolometer chips. These calibrated cameras can measure absolute temperatures in a range from 400 to $2000^{\circ} \mathrm{C}$. A $24 / 7$ operation of the IR camera is achieved by using a water-cooled boroscope and additional purge air which prevents the lens from being contaminated. Furthermore, a rejection unit allows for the camera system to move in and out automatically e.g. in case of a breakdown of the plant air or water supply.

\section{Applications of camera systems in grate firing processes}

\subsection{VIS camera based control of flue gas burnout}

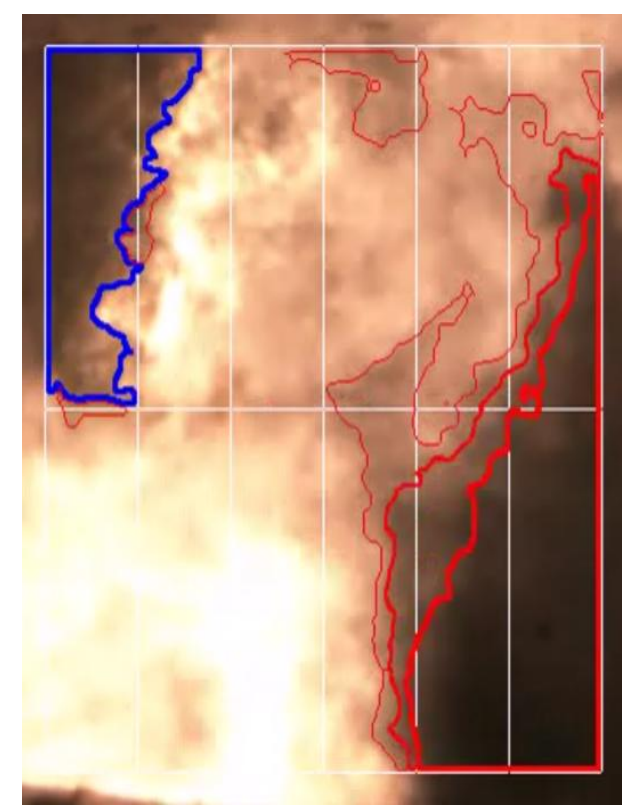

Fig. 3. VIS camera based detection of soot streaks in the flue gas
Emission of incomplete combustion products (e.g. CO and hydrocarbons) is limited by legislation. Especially heterogeneous fuels, such as domestic waste, may cause local combustion conditions to vary considerably. The flue gases entering the flue gas burnout zone exhibit significant local variations of the calorific value and $\mathrm{O}_{2}$ concentration over the cross section (i.e. flue gas streaks). Globally controlled and homogeneous supply of secondary air over the cross section of the flue gas burnout zone requires relatively large combustion chambers to ensure efficient flue gas burnout.

IR and/or video camera-based online detection of the local burnout status of the flue gas over the entire cross section of the flue gas burnout zone enables the local combustion status to be captured. Fig. 3 shows the view with a VIS camera from position 2 (Fig. 1) onto the flue gas burning. In the centre, a bright flame indicates a good burnout of the flue gas. In the lower right corner a strong soot streak can be observed, which indicates an oxygen deficit in this area. In the upper left corner of the image cold material on the grate can be seen.

Using special developed image processing algorithms, the position and size of soot streaks (regions with oxygen deficit) can be detected online. These characteristic quantities are used for fast control of local demand-oriented secondary air supply. In this way, optimum flue gas burnout can even be achieved in relatively small combustion chambers. In particular, formation of incompletely burned flue gas streaks under nonsteady-state combustion conditions can be prevented largely. CO-peaks and elevated concentrations of soot particles are reduced effectively. At low concentrations of soot particles in the ash deposits on the boiler surface, formation of PCDD/F (dioxin) is clearly reduced. 


\subsection{VIS camera based control of fixed bed burnout}

To observe the fixed bed burnout behaviour a VIS camera at the end of the firing grate (position 3, Fig. 1) is installed.

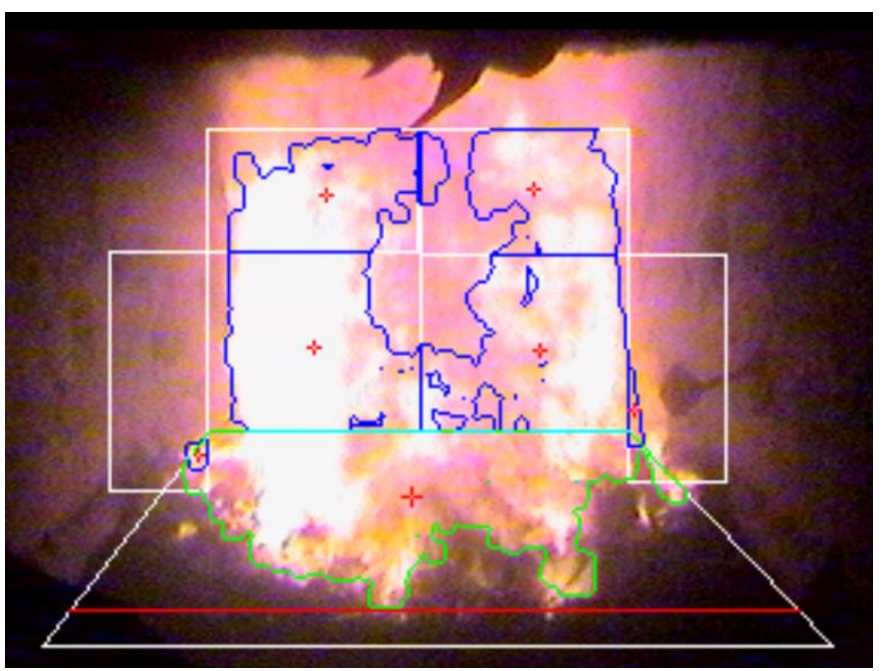

Using an online image processing system, information about length, intensity and area of the burning region can be calculated. This allows for an adaptation of the primary air supply and the transport velocity of the grate to guarantee an efficient carbon burnout of the remaining slag.

Figure 4 shows the VIS image and the calculated information by image processing. The green bordered region indicates the detected combustion zone of the fixed bed burnout with the horizontal red line marking the end of the fire. The centre of gravity (red cross) of this region clearly outlines disadvantageous fire positions. Additional information about the flame characteristics like shape and dynamics can be extracted by analyzing the blue bordered flame region.

Fig. 4. Monitoring of fixed bed burnout with VIS camera

\subsection{IR camera based control of main combustion}

Employing an IR camera at position 2 or 3 (Fig. 1) with a bandpass filter at $3.9 \mu \mathrm{m}$ the behaviour of the main combustion zone in the fuel bed can be observed.

After a digital image filtering, aiming at the minimization of the influence of dust particles and soot in the images, a number of different process information can be extracted out of the filtered image. This information is transferred to the process control system and is used for an online adaptation of process parameters in order to maximize the throughput of the plant as well as to reduce the deviations in steam production and emissions of pollutants. Typical image based process information are the mean temperatures of different grate zones, the position and size of the main burning zone in the fuel bed (Fig. 5), the degree of coverage as the ratio between freshly injected and ignited fuel, the transport speed and the residence time of the combustion material and the dustemitting areas per zone and lane.

The IR camera based system for the optimization of the control of the main combustion is the basis for the new image based detection of empty grate regions presented in section 3 .

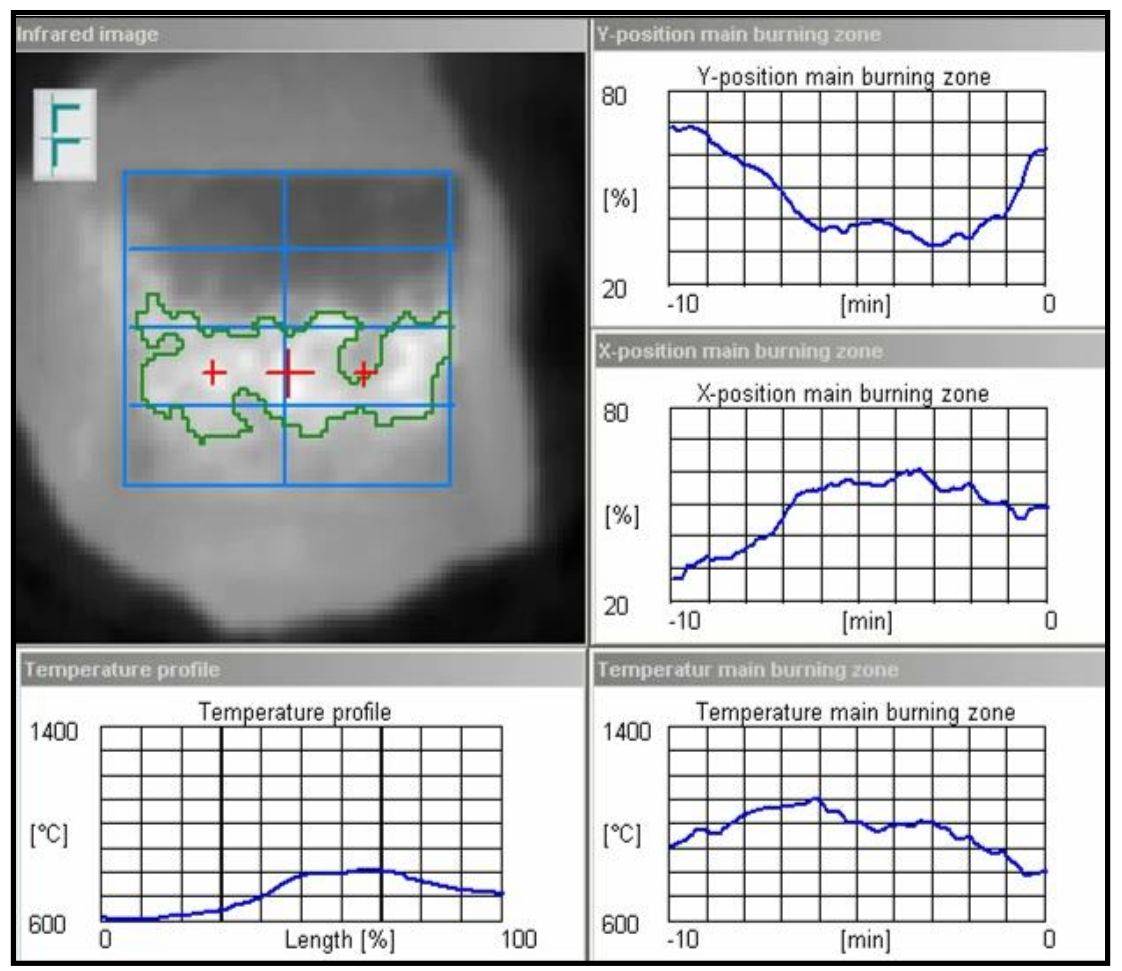

Fig. 5 : Grate segmentation and characteristics of the main combustion zone based on IR camera measurement

Other applications for a camera based optimization can be found in the field of metal recycling [3] or waste incineration in rotary kilns [4], in the cement production or online burner flame analysis [5]. 


\section{Image based detection of empty grate regions}

\subsection{Drop of steam production due to empty grate regions}

A constant steam production - even with varying fuel properties - is managed by adapting the feeding. If the current steam production drops below its set value, the feeding must be increased and vice versa. Unfortunately, there is a big delay between feeding and steam production. Additionally, an excessive increase of the fuel feeding leads to a covering of the combustion zone with fresh (and cold) fuel and thus to a further drop of the steam production. At the moment there is no reliable information available whether there is enough fuel on the grate or not. For this reason and to avoid covering states, the combustion control works very conservatively and frequently does not increase the feeding sufficiently, even if parts of the firing grate are empty. This leads to frequent drops of the steam production. Figures 6 and 7 show this effect. Already half an hour before the steam production starts to drop at 22:15 the IR images show parts of the empty firing grate (especially the division bars between the lanes). At 22:15 large parts of the grate are not sufficiently covered by fuel which leads to an significant drop of the steam production at 22:30. If these situations can be detected automatically by an image processing system, these drops in steam production could be avoided.

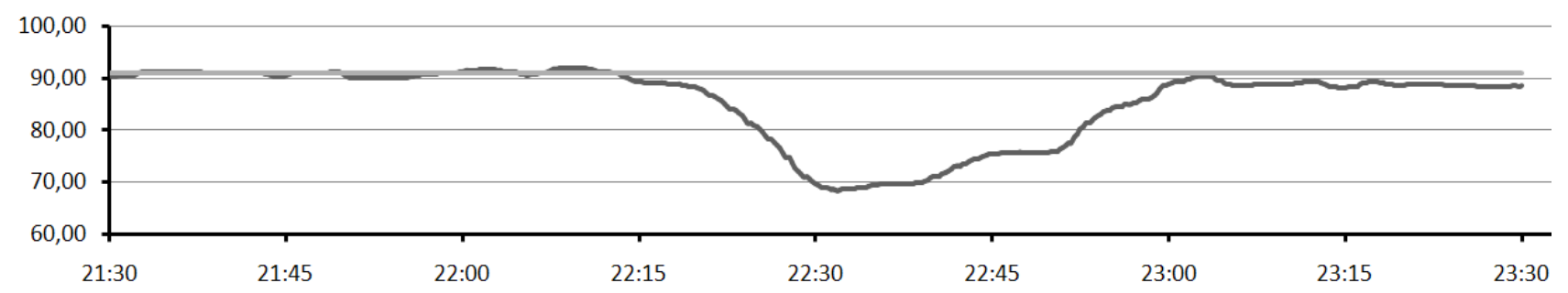

Fig. 6. Evolution of the steam production (set point $91 \mathrm{t} / \mathrm{h}$ ) from $21: 30$ to $23: 30$

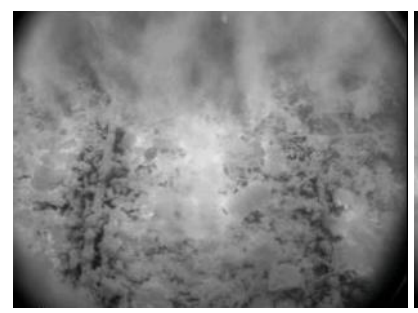

21:45

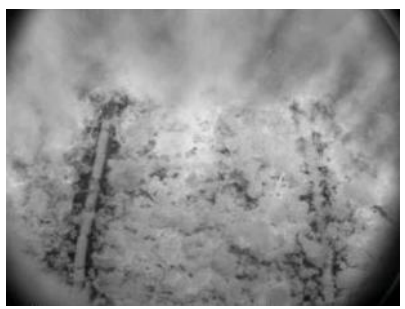

22:00

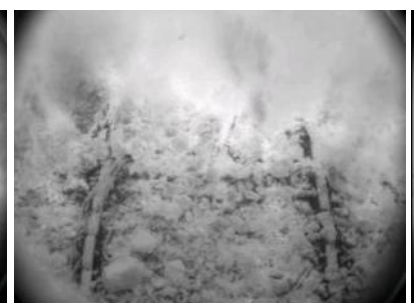

$22: 15$

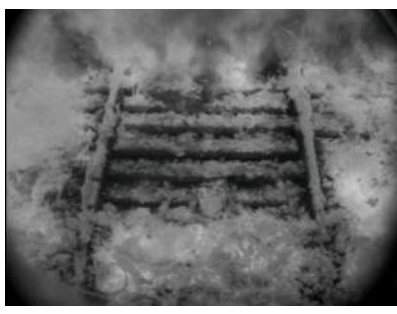

$22: 30$

Fig. 7. IR-Images from $21: 45$ to $22: 30$ (scaled from $600^{\circ} \mathrm{C}$ to $1400^{\circ} \mathrm{C}$ )

\subsection{Image processing for empty grate detection}

Here a new image processing algorithm is presented, which allows the reliable detection of empty grate regions. Based on that, parameters are derived that can be used in the combustion control system. The main idea of the new algorithm is to use a simplified image of an empty grate as template. By correlating the template with the current image in a defined neighbourhood, a new image can be derived, which contains the similarity of the image with the template for each pixel.

Figure 8 (upper, left) shows the IR image $\mathrm{g}$ which was geometrically transformed to get a virtual rectangular view of the grate (neglecting geometric distortion). Additionally, the simplified grate template $\mathrm{h}$ is depicted (Figure 8 , upper right).

For the calculation of the correlation image $\mathrm{r}$ for each pixel $(\mathrm{x}, \mathrm{y})$ the corresponding position in the IR image $\mathrm{g}$ and the template image $\mathrm{h}$ is regarded. The calculation of correlation is performed using a window around ( $\mathrm{x}, \mathrm{y}$ ) with a size of $(2 \mathrm{M}+1)$ rows and $(2 \mathrm{~N}+1)$ columns (red windows in Figure 8$)$. For the calculation of each $r(x, y)$ this window is cropped out of the IR image as well as out of the template image. The cropped parts $\mathrm{g}_{\mathrm{c}}$ and $\mathrm{h}_{\mathrm{c}}$ are normalized by subtracting their mean values and dividing by their standard deviations:

$$
g_{c}^{N}(x, y)=\frac{g(x, y)-\operatorname{mean}\left(g_{c}\right)}{\operatorname{stdev}\left(g_{c}\right)} \quad \text { and } \quad h_{c}^{N}(x, y)=\frac{h(x, y)-\operatorname{mean}\left(h_{c}\right)}{\operatorname{stdev}\left(h_{c}\right)}
$$


With the normalized cropped parts of the IR image $g_{c}^{N}$ and the template image $h_{c}^{N}$ the correlation $r(x, y)$ at position $(\mathrm{x}, \mathrm{y})$ is defined by

$$
\mathrm{r}(\mathrm{x}, \mathrm{y})=\frac{1}{(2 \mathrm{M}+1)(2 \mathrm{~N}+1)} \sum_{m=-M}^{M} \sum_{n=-N}^{N} \mathrm{~g}_{\mathrm{c}}^{\mathrm{N}}(\mathrm{x}+\mathrm{n}, \mathrm{y}+\mathrm{m}) \cdot \mathrm{h}_{\mathrm{c}}^{\mathrm{N}}(\mathrm{x}+\mathrm{n}, \mathrm{y}+\mathrm{m})
$$

The correlation value $\mathrm{r}(\mathrm{x}, \mathrm{y})$ is calculated for all positions and registered into a correlation image. In this correlation image high values indicate regions with a strong similarity between the current IR image and the empty grate (Figure 8, lower left).

Now, the empty grate region could be detected using a correlation threshold. Nevertheless, in order to integrate the empty grate information into a process control system it is more reasonable to determine signals that describe the state of the grate load continuously for different grate regions. Therefore the mean value of the correlation is calculated for user defined regions of the IR image. Conveniently, these user defined regions coincide with separately controllable zones of the grate (Figure 8 , lower right).

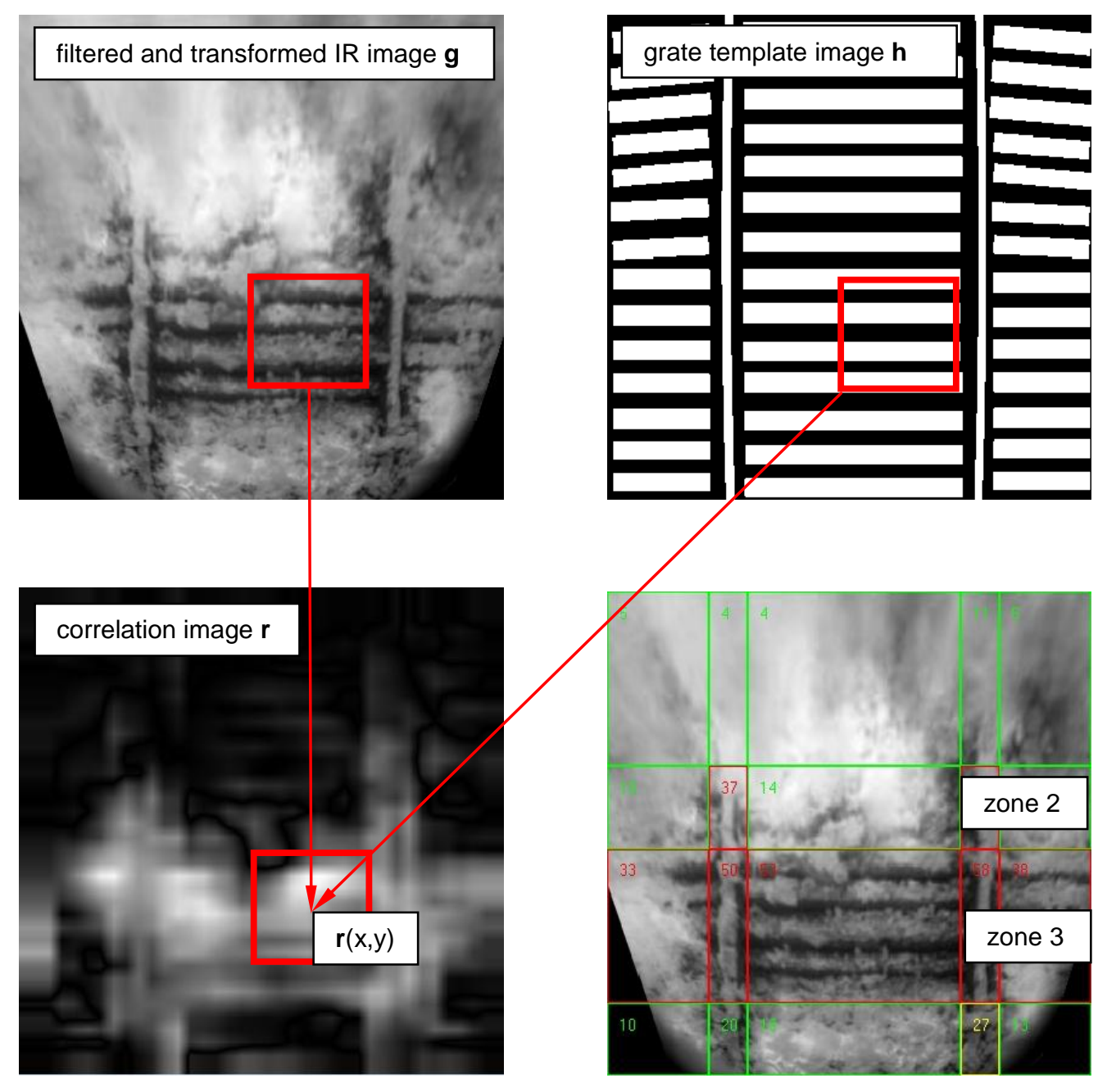

Fig. 8. Image processing steps for empty grate detection

\subsection{Results}

In Figure 9 the values of the empty grate correlation for zone 2 and zone 3 are depicted over time. Additionally the evolution of the steam production is plotted. Already half an hour before the steam production begins to drop the correlation for zone 3 is slightly growing. At about 22:05 a significant increase of the correlation for zone 3 can be detected. Thus already 15 minutes before the steam production starts to decrease, the new empty grate correlation signal for zone 3 significantly points at a lack of fuel. Using this information an optimized process control system can increase the fuel feeding early and thus prevent the steam production from dropping. At 22:20, when the steam 
production begins to decrease, also the empty grate correlation for zone 2 rises rapidly. Even though this signal gives no significant advantage concerning temporal aspects, it clearly shows that the reason is the lack of fuel.
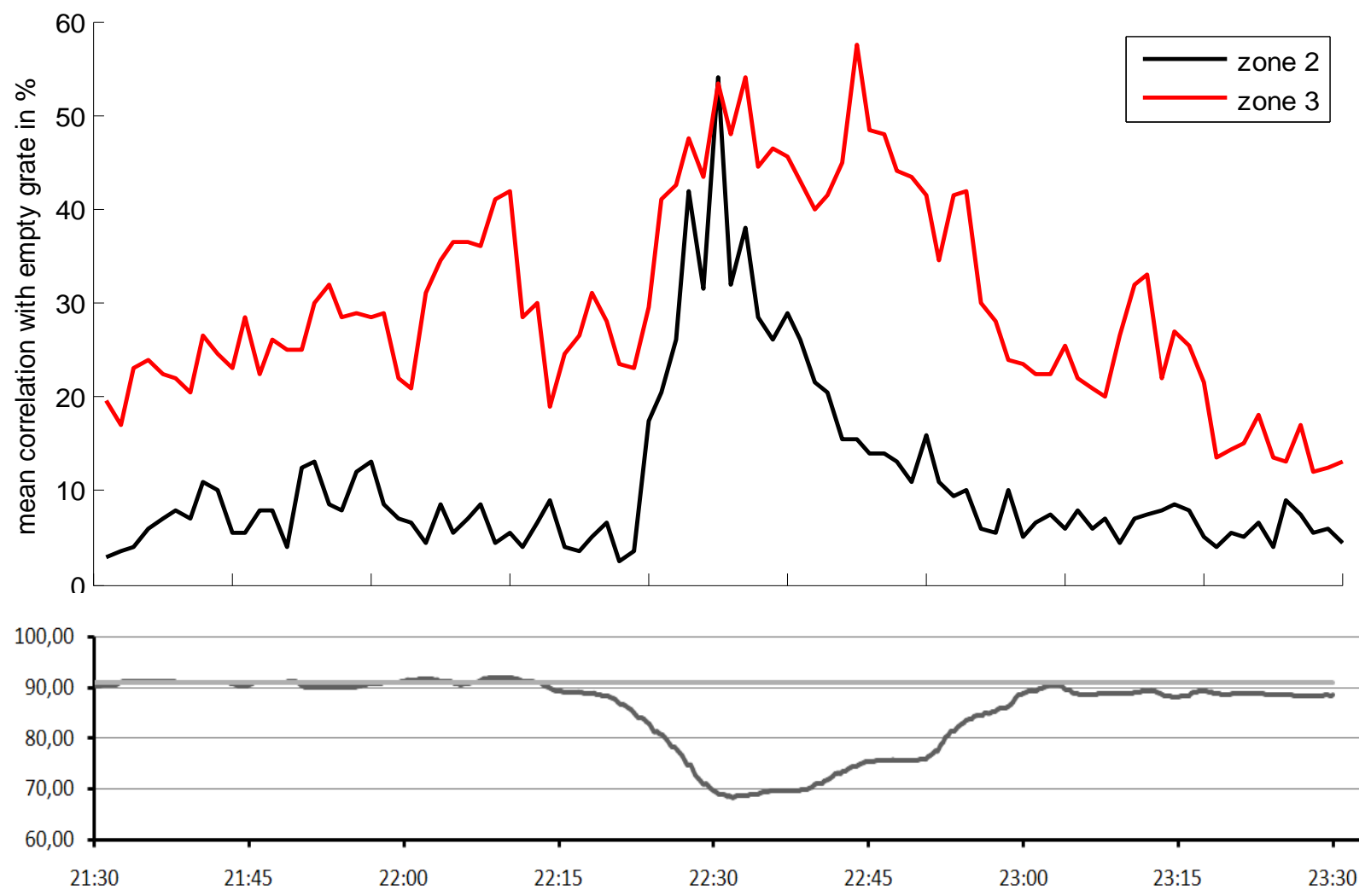

Fig. 9. Empty grate correlation over time for zone 2 and 3 compared to steam production

\section{Conclusion}

In firing processes for waste or biomass incineration camera systems can be used for different measurement tasks. Cameras in the VIS range are applied for fixed bed or flue gas burnout monitoring. IR cameras with a bandpass filter at $3.9 \mu \mathrm{m}$ are used for the measurement of solid bed temperature distribution, because at this spectral range flames are almost transparent. Using an image processing system like INSPECT pro control ${ }^{\circledR}$, new signals can be derived online from the camera images and transmitted to the control system for a process optimization. With this camera based process control CO-peaks could be reduced by $80 \%$ and the CO-content by $50 \%$. Additionally the margin of deviation of the steam production could be reduced by $10-30 \%$. As a result the degree of efficiency of the boiler could be increased by $2 \%[2]$.

The process control can be further improved by using additional camera based information on the load state of the grate. In this paper a new image processing algorithm is presented, which calculates new signals from the IR images indicating a low load state of different regions of the grate. These signals provide a good prediction for drops of the steam production. Utilizing these signals for a better adaptation of the fuel feeding, the deviation of the steam production can be further reduced.

\section{REFERENCES}

[1] Zipser S., Gommlich A., Matthes J., Keller H.B., "Combustion plant monitoring and control using infrared and video cameras". In: Proc., IFAC Symposium on power plants and power systems, Kananaskis, Canada 2006.

[2] Keller H.B., Matthes J., Zipser S., Schreiner R., Gohlke O., Horn J., Schönecker H., "Cameras for combustion control of highly fluctuating fuel compositions". VGB PowerTech, 3/2007.

[3] Matthes J., Waibel P., Keller H.B., "A new infrared camera-based technology for the optimization of the Waelz process for zinc recycling." Minerals Engineering, 24(2011) P.944-949

[4] Waibel P., Vogelbacher M., Matthes J., Keller H.B., "Infrared camera-based detection and analysis of barrels in rotary kilns for waste incineration." In: Proc. Quantitative Infrared Thermography 2012, Naples (to appear).

[5] Gehrmann H.J., Kolb T., Seifert H., Waibel P., Matthes J., Keller H.B. "Co-combustion of low rank fuels in power plants." 30th Internat. Conf. on Thermal Treatment Technologies (IT3) and Hazardous Waste Combustors, Jacksonville, Fla., May 10-13, 2011 